\title{
Article
}

\section{An overview of early investigational drugs for the treatment of human papilloma virus infection and associated dysplasia}

Hampson, Lynne, Martin-Hirsch, Pierre and Hampson, Ian N Available at http://clok.uclan.ac.uk/13751/

Hampson, Lynne, Martin-Hirsch, Pierre and Hampson, Ian N (2015) An overview of early investigational drugs for the treatment of human papilloma virus infection and associated dysplasia. Expert Opinion on Investigational Drugs, 24 (12). pp. 1529-1537. ISSN 1354-3784

It is advisable to refer to the publisher's version if you intend to cite from the work. http://dx.doi.org/10.1517/13543784.2015.1099628

For more information about UCLan's research in this area go to http://www.uclan.ac.uk/researchgroups/ and search for <name of research Group>.

For information about Research generally at UCLan please go to http://www.uclan.ac.uk/research/

All outputs in CLoK are protected by Intellectual Property Rights law, including Copyright law. Copyright, IPR and Moral Rights for the works on this site are retained by the individual authors and/or other copyright owners. Terms and conditions for use of this material are defined in the policies page.

\section{CLoK}

Central Lancashire online Knowledge www.clok.uclan.ac.uk

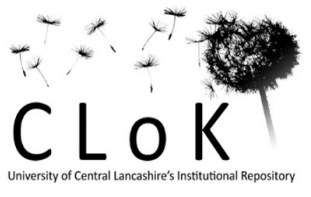


An overview of early investigational drugs for the treatment of human papilloma virus infection and associated dysplasia.

Lynne Hampson*, Pierre Martin-Hirsch ${ }^{+}$and Ian N Hampson*

* University of Manchester Viral Oncology Laboratories, Research Floor, St Mary’s Hospital, Oxford Road, Manchester M13 9WL.

${ }^{+}$Department of Obstetrics and Gynaecology, Royal Preston Hospital Sharoe Green Lane, Fulwood, Preston PR2 9HT 


\begin{abstract}
Introduction: Infection with hHigh-risk types of HPV (HR-HPV) isare the main aetiological agent forcause of invasive cervical cancer (ICC) from which there are $>270,000$ deaths per annum world-wide with over $85 \%$ of these occurring in lowresource countries. Ablative and excisional treatment modalities are restricted for use with high-grade pre-cancerous cervical disease with HPV infection and low-grade dysplasia is-currently managed by a watch-and-wait policy.
\end{abstract}

Areas Covered: A variety of different pharmacological approaches have been investigated as non-destructive alternatives for the treatment of HR-HPV infection and associated dysplasia.. In this review, the authors These are discussed-developments in this area dealing with efficacy, ease-of-use (physician or self-applied), systemic or locally applied, side-effects, cost and finally anyand associated risks. The main focus will be discussion of the perceived impact on current clinical practice of a self-applied, effective and safe pharmacological anti-HPV treatment.

Expert Opinion: Current prophylactic HPV vaccines are expensive, only protect against the two most prevalent malignant disease-associated HPV types and have little effect in women who are already infected. There are therapeutic vaccines under development but these are also HPV type-restricted. At present, the developed nations use national cytology screening and surgical procedures to treat only women identified with HPV-related high-grade dysplastic disease. However, since HPV testing is rapidly replacing cytology as the test-of-choice, a suitable topically-applied and low-cost antiviral treatment could be an ideal solution for treatment of HPV infection per se with test-of-cure carried out by repeat HPV testing. Cytology would only then be necessary for women who remained HPV positive. Although of significant benefit in the developed countries, this could revolutionise the management of this disease in the developing nations which lack both the infrastructure and resources to establish national cytology screening programs. Combining such a treatment with self-sampled HPV testing could provide a very cost-effective solution to the huge burden of HPV related disease in such low-resource settings. 


\section{Introduction}

Infection with high-risk (HR) types of HPV is now well established as the main aetiological agent for invasive cervical cancer (ICC) ${ }^{1-3}$ and globally there are $>270,000$ deaths from this disease per annum with over $85 \%$ of these occurring in low resource settings where it comprises $>23 \%$ of all female malignancies ${ }^{4,5}$. The development of ICC can take 10-20 years and is preceded by - oncogenic HPV related pre-invasive pathologies which are characterised as either low-grade (CIN1) or high-grade cervical intraepithelial neoplasia (CIN2/3) ${ }^{1}$. Such lesions can be are typically screen detected by cervical cytology testing where they are diagnosed as either borderline atypical squamous cells of undetermined significance (ASCUS), low-grade squamous intraepithelial lesions (LSIL) or high-grade squamous intraepithelial lesions (HSIL) ${ }^{6}$ (See Figure 1). If cervical cytology is abnormal, screening programmes warrantedrecommend diagnostic and management guidelines.; Diagnosis involves ćolposcopy and when the is then performed where diagnosis of high grade CIN grade is subsequentlyconfirmed by biopsy, treatment is mandated. and histopathology.

The reduction in ICC related mortality in the developed world has been largely dependent on organised cytology screening and similar trends in cervical cancer mortality have been achieved by the practice of organised single screen and treat in low resource settings ${ }^{7}$. However, in the majority of the poorer nations, lack of resources and health education means that most pre-invasive cervical disease remains undiagnosed and untreated. Thus, where resources are limited, low-cost screening and alternative treatment options are clearly a high priority.

Current treatment options in clinical practice are either by ablative (destructive) or excisional modalities which have similar success rates but have different morbidities ${ }^{8}$. In the developed nations, Large Loop Excision of the Transformation Zone LLETZ (aka loop electrosurgical excision procedure - LEEP ${ }^{9}$ ) is used in the majority of colposcopy clinics. Over $80 \%$ of these procedures are performed under local analgesia and the whole of the transformation zone is available for subsequent histological examination. Although highly effective (80-95\%), this procedure is associated with a risk of primary/secondary haemorrhage, prolonged vaginal discharge, infection and a risk of preterm delivery in subsequent pregnancies which can be problematic in low resource countries ${ }^{10,11}$. Ablative cold coagulation and cryotherapy are often advocated for use in these settings since these are low cost, require minimal infrastructure and can 
be carried out by trained non-medical health professionals. However, some studies have suggested that these treatments have a higher failure rate when compared to other modalities ${ }^{8,12}$.

Aft is very clear that, whilst effective, ablative and destructive approaches to treatment have their limitations and in the small minority of cases can lead to persistent $\underline{\text { disease requiring more radical treatment which might ultimately require hysterectomy. }}$ Bue to the associated morbidity and potential complications they are restricted for use with high-grade disease and can only be repeated a finite number of times until hysterectomy is inevitable.Furthermore, implementation of these procedures requires appropriately trained medical staff and facilities which are often not available in lowresource settings. Moreover, any treatment associated complications are also much more difficult to manage in such locations.

Prevention is an obvious solution to these problems and the two currently available prophylactic vaccines Cervarix ${ }^{\circledR}$ and Gardasil ${ }^{\circledR}$ have now been implemented in many of the developed nations ${ }^{13}$ although limitations of their use are HR-HPV 16/18 type restriction and high cost. Even though a prophylactic nonavalent vaccine is under development it is still likely to be expensive. ${ }^{14}$ _SinceFurthermore, since thesese are prophylactics, an effective pharmacotherapy for HPV infection and any associated underlying dysplasia would be an ideal solution for women already infected with HPV. Thus implementation of a well-tolerated and safe non-destructive treatment modality would permit this to be used against HPV infection per se, in addition to low-grade disease, for which there are currently no treatment options. This would be particularly advantageous in low resource settings where low-cost HPV tests, such as Care HPV (Qiagen), combined with self-sampling, could provide an alternative to cytology for the basis of treatment decisions with test-of-cure carried out by follow-up repeat HPV testing ${ }^{15}$. Those women with persistent HPV infection could then either be re-treated or referred for conventional colposcopy followed by surgery if this was deemed necessary. However, for such a pharmacological treatment to be implemented, it would clearly need to be reasonably priced and have comparable success rates to current surgical procedures.

There are a variety of non-surgical approaches which have been evaluated in clinical trials for the treatment of HPV related cervical dysplasia although in 2004 these were not recommended due to side-effects and limited efficacy ${ }^{16}$. However, recent improvements in their application combined with the development of new modalities 
means some of these approaches have now "come-of-age" ${ }^{17}$ and these will now b_e discussed with respect to their ability to fulfil the aforementioned criteria.

\section{Photodynamic Therapy (PDT)}

PDT is a minimally invasive procedure which uses either topical or systemic treatment with a photo-sensitiser followed by exposure to light of an appropriate wavelength and it has been used to treat both low and high grade cervical dysplasia with varying degrees of success ${ }^{18}$. Systemic photo-sensitisers, such as Photfrin ${ }^{\circledR}$, can cause problems with non-specific dermal photosensitisation. Aalthough a recent small series study, using the topical photo-sensitiser hexaminolevulinate, has reported high success rates of 95\% clearance of CIN lesions with 83\% (5/6 patients) clearance of HPV16/18 ${ }^{19}$. These findings clearly indicate that this procedure has considerable potential to provide an effective non-surgical treatment for both low and high-grade HPV related dysplasia, if proven in larger studies. However, since it is physician applied, with the attendant and equipment and cost implications, it is very unlikely to be used for the treatment of HPV infection or disease in low resource settings per se. This implies that PDT would thus be restricted to the treatment of histologically confirmed dysplasia.

\section{Cidofovir}

The antiviral drug cidofovir is currently licensed for the treatment HIV related CMV retinitis and it has been used extensively off-licence for the treatment of low-risk (LR) HPV laryngeal warts ${ }^{20}$. It has also been used to treat HR-HPV related cervical dysplasia ${ }^{21}$ and more recently with some success where 14/23 (>60\%) of women with pre-treatment biopsy confirmed CIN2 were found to be histologically normal following 3 physician-applied local applications of cidofovir ${ }^{22}$. However, since this drug is both mutagenic ${ }^{23}$ and carcinogenic in animals its use for the treatment of HPV related benign and pre-malignant pathologies has proved controversial ${ }^{24}$. Given these concerns, it is not likely that the use of locally applied cidofovir would be approved for the treatment of cervical HPV infection per se even when low grade dysplasia is alse present. Furthermore, at a cost of approximately $\$ 1000$ for a $5 \mathrm{ml}$ vial of $75 \mathrm{mg} / \mathrm{ml}$ it is also expensive which would limit its use in resource constrained settings.

\section{Imiquimod}


The immune activator imiquimod does not have direct antiviral activity but activates cytokines which subsequently promote immunological clearance of virus ${ }^{25}$. Although local application of this agent has been used extensively to treat LR-HPV related genital warts, its efficacy was found to be questionable in a recent systematic review ${ }^{26}$. In a study carried out in Taiwan, women who had been treated with surgery for cervical and vaginal dysplasia, but had persistent HPV infection both with and without dysplasia, were treated with locally applied 5\% imiquimod cream for 6 weeks which showed $65 \%$ clearance of HPV infection ${ }^{27}$. Moreover $>60 \%$ clearance of cervical dysplasia was also reported but only in 4/6 patients. A very similar study, also carried out in Taiwan, used 5\% imiquimod cream for 8 weeks and showed a 76\% clearance of HPV presumably due to the longer treatment period ${ }^{28}$. However, a comparison of imiquimod therapy to standard surgical intervention for CIN treatment concluded that disease recurrence was the same in both groups and yet side effects such as fever, fatigue, headache, myalgia, nausea, chills and vaginal discharge were considerably worse in women treated with imiquimod ${ }^{29}$. Compared to cidofovir, imiquimod is reasonably priced and there is no doubt that it is effective in some women.

Furthermore, it can be self-applied although its efficacy is not better than surgical procedures and it can produce unpleasant side-effects for the duration of treatment limiting compliance. To illustrate, 39 (46\%) of 84 women treated with 5\% imiquimod for HPV-related vulval intraepithelial neoplasia (VIN), reported grade 3 or 4 adverse $\underline{\text { events }}^{30}=$

\section{5-Flurouracil (5-FU)}

5-FU is pyrimidine analogue cytotoxic agent used in the treatment of cancer and topical application of a $5 \%$ solution of this drug for 8 weeks over a 16 week period has been used to treat CIN2 ${ }^{31}$. This produced regression of disease in $96 \%$ of patients after 6 months follow up although only 50\% had normal pathology and were also negative for HPV. It is well known that 5-FU has very significant toxic side-effects associated with both local and systemic use and these effects can be difficult to predict demonstrating marked variations between individuals ${ }^{32}$. Since $5-\mathrm{FU}$ is so toxic, its application to the cervix was physician-applied and its reported efficacy against CIN2 and HPV was no better than current surgical procedures. Given these observations and safety concerns, it is very clear that this drug would not be approved for the treatment of HPV infection per se or even low-grade disease in the general population. 


\section{Interferon}

Ten intra-lesional injections of 3mIU of the endogenous human antiviral protein interferon-alpha over 3-4 weeks were used to treat 45 cases of CIN1-3 and 30 of carcinoma in situ (CIS) ${ }^{33}$. All women returned to normal cytology and were HPV negative which was maintained during a six year follow-up period. This study was a simple proof-of-concept with no control arm and yet, given the marked efficacy observed, it is curious that there have been no further more robust phase 2 studies carried out on this indication. This could be related to the need for direct intra-lesional injection and with interferon-alpha being a biological, it is veryquite expensive. Furthermore, systemic interferon does cause significant side-effects such as flu like symptoms and low mood. However, there are now microencapsulated forms of this drug available which can be used for direct topical application although it is very likely that cost will still be an issue ${ }^{34}$.

\section{Therapeutic Vaccines}

Although not strictly pharmacotherapy, a variety of therapeutic HPV vaccines have been produced which are at various stages of clinical development and many of these are summarised in a recent review by Rosales and Rosales ${ }^{35}$. One of the most interesting is the live vaccinia virus based MVA-E2 vaccine which was initially tested in Mexico where 36 women received direct intrauterine injection of the vaccine once weekly for 6 weeks. This produced a return to normal cytology in $85 \%$ of patents although HPV was still present in 50\% of those treated ${ }^{36}$. The same authors carried out a more comprehensive study of the efficacy of MVA-E2 on HPV related dysplastic lesions in 1176 women and 180 men by direct injection of the vaccine into the uterus, vulva, urethra or anus ${ }^{37}$. The outcome was elimination of HPV DNA is $83 \%$ of patients treated with $89 \%$ of women and $100 \%$ of men showing normal histology post-treatment. Although these results are very encouraging, there are clearly safety issues concerning the use of live vaccinia recombinant vaccines. Even though these authors used the attenuated Ankara strain of vaccinia ${ }^{38}$ and stated the treatment was well tolerated with no adverse reactions, there are real concerns surrounding the release of such recombinant live virus vectors into the general population. 
More recently a DNA-based HPV vaccine VGX-3100 has been developed which was delivered by 5 intramuscular injections combined with in vivo electroporation. This was initially used to treat 18 women with persistent CIN2/3 which demonstrated a convincing immune response although efficacy was not reported in this study ${ }^{39}$. A phase 2 trial has also been carried out using the same vaccine to treat a total of 148 women with CIN2/3 and CIN3 (Trial ID No.

NCT01304524) although this has not yet reported.

\section{Pre-Clinical and Clinical Trials Carried out on Natural Products}

In addition to the previously discussed synthetic small-molecule, protein and vaccine based therapies, a variety of natural products have also been investigated for antiHPV activity ${ }^{40}$. Examples of these are, ferulic acid ${ }^{41}$, artemisinin ${ }^{42-44}$, withaferin A ${ }^{45}$, resveratrol ${ }^{46}$, (-)-epigallocatechin-3-gallate ${ }^{47}$, ursolic acid ${ }^{48}$, berberine ${ }^{49}$, jaceosidin ${ }^{50}$, curcumin ${ }^{51}$ and indole-3-carbinol ${ }^{52}$. Although all these products have shown activity against cultured HPV positive cervical carcinoma cell lines very few have been trialled in the clinic. Notable exceptions were:-

- Oral administration of the artemisinin derivative Arteminol R for 28 days was shown to improve both clinical symptoms and disease marker expression in 10 women with advanced cervical cancer with no serious adverse events ${ }^{44}$.

- Ninety eight women were recruited for a phase 2 randomised trial of placebo or 800 mgs of orally administered green tea polyphenol (-)-epigallocatechin-3-gallate once daily for 4 months which showed no difference in CIN or HPV status between placebo or test ${ }^{47}$.

- Two hundred and eighty two HPV positive women with no dysplasia were treated with either a-curcumin containing formulations or placebo controls for 30 days which showed a modest improvement in HPV clearance (87\% Test Vs 73\% placebo). ${ }^{51}$.

- Thirty women with biopsy confirmed CIN2/3 were randomised to receive $200 \mathrm{mg}$ or $400 \mathrm{mg}$ of indole-3-carbinol or placebo orally once a day for 12 weeks.

Although there was a statistically significant regression of dysplasia in the test group, there was no detectable clearance of HPV when compared to placebo ${ }^{52}$. 
Most Human Imunodeficiency VirusHIV PI's are small molecule, peptide mimetic drugs which target the HIV aspartyl protease that is essential for the production of infectious virions and these agents have been shown to have pleiotropic effects against viral replication at various stages of the virus life cycle ${ }^{53}$. Futhermore, it was also shown that selective off-target effects of these drugs on the mammalian proteasome contributes to their activity against HIV ${ }^{54-56}$. Since HPV, and many other viruses, are known to deregulate the proteasome ${ }^{57}$, it was considered that HIV PIs may have broader activity against other viruses. Preclinical studies demonstrated this against HPV which showed lopinavir to be the most active HIV PI against cultured HPV positive cervical carcinoma cell lines ${ }^{58}$. However, although lopinavir was the most effective HIV PI against HPV in vitro, this was at higher concentrations than can be achieved from normal oral dosing for HIV therapy ${ }^{59}$. Indeed a recent comparison of non-PI and PI-based highly active antiretroviral therapy (HAART), both with and without oral lopinavir, was carried out in HIV positive women which showed no effect on the prevalence of cervical HPV infection ${ }^{60}$. Nevertheless, previous in vitro studies have defined at least part of the mode-of-action of lopinavir against HPV 61 and several HIV PI's are now well known to have both anticancer and antiviral properties ${ }^{62-66}$. Moreover ${ }_{2}$ lopinavir has also been shown to have activity against severe acute respiratory syndrome (SARS) and, more recently, middle eastern respiratory syndrome (MERS) coronaviruses ${ }^{67-69}$.

Lopinavir is normally prescribed as a 4:1 mixture with ritonavir (Kaletra ${ }^{\circledR}$ ) and earlier in vitro studies suggested that the presence of ritonavir may actually be detrimental to the anti HPV activity of this compound ${ }^{58}$. Ritonavir as a mono-therapy has been shown to have anti-invasive and anti-proliferative activity against cells derived from preinvasive CINs but little activity against cells derived from more advanced cervical carcinomas ${ }^{70}$.

With regard to clinical trials carried out on treatment of HPV related cervical dysplasia with HIV PI's, the University of Texas is currently recruiting for a phase II single-arm intervention trial of oral nelfinavir in patients with CIB 2/3 or $3^{71}$ (Trial Id. No. NCT01925378) which is expected to complete in December 2016. A phase 1 single-arm, proof-of-concept trial of topically applied Lopimune (Generic Kaletra, CIPLA) has also been carried out. Standard Lopimune soft--gelatin capsules (133.3mg Lopinvir + 33.3mg Ritonaveir ) -were given twice daily as a vaginal pessary for 2 weeks to 23 Kenyan women diagnosed with HPV positive HSIL ${ }^{72}$. Follow up of 
these women at 3 months showed $60 \%$ had regained normal pathology with $18 \%$ regressing to low-grade disease producing a combined positive response in $78 \%$ with clearance of HPV seen in 50\% of these women. Clearly, these observations support further investigation on the ability of HIV PI's to treat HPV infection per se in addition to any associated dysplasia.

\section{Expert Opinion}

TAs stated there is no clinically approved pharmacological treatment for HPV infection or associated cervical dysplasia and it is clear that Eexcisional swith surgery andor ablative procedures will continue to be the recommended treatment within opportunistic or organised screening programmes for pre-invasive disease as fillustrated in Figure 1). restricted for use with women diagnosed with high-grade disease (HSIL or CIN2/3) as illustrated in Figure 1.

A potential new approach would be a 'mass' conservative medical effective treatment for HPV and associated disease. The problem is that HPV infection is very common, often producing no abnormal pathology and has a high rate of spontaneous clearance, most particularly in the early stages of disease and in low grade lesions and-in younger women aged $<23$ years ${ }^{73}$. In view of this, a watch and wait policy is considered to be best clinical practice for the management of HPV infection and associated low-grade dysplasia (LSIL or CIN1) since excisional and ablative methods are necessarily destructive with the added risk of treatment associated side-effects and morbidity ${ }^{10,11}$. Of particular concern is that in countries that do not have prophylactic vaccination or cytology screening, women and their partners who acquire, albeit transient, HR-HPV infection will constitute a reservoir of infectious virus which clearly enhances dissemination to other individuals. As discussed,the majority will clear the virus but the minority who develop persistent HPV infection are at increased risk of developing associated dysplasia. A potential solution to this problem would be a "catch-all” pharmacological antiviral treatment which also proved effective against dysplasia which may or may not be present. Such a treatment could then be prescribed on the basis of a positive test for HR-HPV with test-of-cure by repeat HPV testing. However, the rate of spontaneous clearance of HPV16/18 in placebo control groups can be $>70 \%$ within six weeks ${ }^{51}$ which implies that such a pharmacotherapy would necessarily have to be extremely well tolerated with minimal risk of complications. This raises the question, are any of the previously discussed treatments suitable? 
Locally applied PDT, Cidofovir, Imiquimod, 5FU and Interferon all showed significant efficacy against dysplastic lesions although, all but Imiquimod, were physician applied. Since there are also issues of safety, side-effects and cost it is unlikely that any of these modalities will ever be used for the treatment of HPV or pre-invasive disease.HPV infection in the absence of high grade dysplasia.

With regard to therapeutic vaccines, there is no doubt that the physician applied vaccinia recombinant MVA-E2 proved extremely effective although there are very real safety concerns with this type of treatment which will undoubtedly limit its use. The DNA based vaccine VGX-3100 could provide the means to treat HPV infection per se although its efficacy is not yet known and, like all vaccinations, it is a systemic treatment with associated risks and the cost is currently unknown.

A variety of preclinical studies have been carried out on the activity of different phytochemicals in HPV positive cervical carcinoma cell lines although most of these do not translate into useful clinical efficacy. The possible exception to this could be Arteminol $\mathrm{R}$ although this was only used to treat 10 women with advanced disease and clearly needs more thorough investigation.

Finally, as regards off licence use of HIV PI's, the proof-of-concept trial on self-applied topical lopinavir (Kaletra) is a very promising indication but clearly needs larger phase 2 trials to establish efficacy. Most significantly, since Kaletra is currently licensed for the long-term systemic treatment of HIV positive pregnant women and children ${ }^{74}$ it is comparatively safe when compared to the other previously discussed topical agents. As regards cost, the generic form of Kaletra (Lopimune) was approximately $£ 15$ per patient treated as purchased from a Kenyan pharmacy.

In summary, in order for a it is very clear that an effective, inexpensive, nonsurgicalpharmacological treatment for HR-HPV and associated dysplasia to be implemented widely it would need to satisfy the following criteria:-

- Be self-applied

- Be non-destructive

- Have minimal side-effects and be non-mutagenic

- Have efficacy against HPV and associated dysplasia

- Be affordable

, self-applied treatment with minimal side effects would have great potential for the treatment of HPV and related cervical dysplasia most particularly in low resource settings. Out 0 Of the previously discussed treatmentsmodalities, it is our opinion that

\begin{tabular}{l} 
Formatted: Font: (Default) Times New Roman, $12 \mathrm{pt}$ \\
\hline Formatted: Font: (Default) Times New Roman, $12 \mathrm{pt}$ \\
\hline Formatted: Font: (Default) Times New Roman, $12 \mathrm{pt}$ \\
\hline Formatted: Font: (Default) Times New Roman, $12 \mathrm{pt}$ \\
\hline Formatted: Font: (Default) Times New Roman, $12 \mathrm{pt}$ \\
\hline Formatted: Bullets and Numbering \\
\hline Formatted: Font: (Default) Times New Roman, $12 \mathrm{pt}$ \\
\hline Formatted: Indent: First line: $0 \mathrm{~cm}$
\end{tabular}



areprovide the most promising candidates_to date.

\section{References}

1. Bosch FX, Lorincz A, Munoz N, Meijer CJ, Shah KV. The causal relation between human papillomavirus and cervical cancer. J Clin Pathol 2002 Apr;55(4):244-65.

2. zur Hausen H. Papillomavirus infections--a major cause of human cancers. Biochim Biophys Acta 1996 Oct 9;1288(2):F55-78.

3. Walboomers JM, Jacobs MV, Manos MM, Bosch FX, Kummer JA, Shah KV, et al. Human papillomavirus is a necessary cause of invasive cervical cancer worldwide. J Pathol 1999 Sep;189(1):12-9.

4. Parkin DM, Pisani P, Ferlay J. Estimates of the worldwide incidence of 25 major cancers in 1990. International journal of cancer Journal international du cancer 1999 Mar 15;80(6):827-41.

5. Temmerman M, Tyndall MW, Kidula N, Claeys P, Muchiri L, Quint W. Risk factors for human papillomavirus and cervical precancerous lesions, and the role of concurrent HIV-1 infection. Int J Gynaecol Obstet 1999 May;65(2):171-81.

6. Lindeque BG. Management of cervical premalignant lesions. Best Pract Res Clin Obstet Gynaecol 2005 Aug;19(4):545-61.

7. Sankaranarayanan R, Nene BM, Shastri SS, Jayant K, Muwonge R, Budukh AM, et al. HPV screening for cervical cancer in rural India. N Engl J Med 2009 Apr 2;360(14):1385-94.

8. Martin-Hirsch PL, Paraskevaidis E, Kitchener H. Surgery for cervical intraepithelial neoplasia. Cochrane Database Syst Rev 2000(2):CD001318.

9. $\quad$ Prendiville W, Cullimore J, Norman S. Large loop excision of the transformation zone (LLETZ). A new method of management for women with cervical intraepithelial neoplasia. Br J Obstet Gynaecol 1989 Sep;96(9):1054-60.

10. Founta C, Arbyn M, Valasoulis G, Kyrgiou M, Tsili A, Martin-Hirsch P, et al. Proportion of excision and cervical healing after large loop excision of the transformation zone for cervical intraepithelial neoplasia. BJOG 2010 Nov;117(12):1468-74.

11. Kyrgiou M, Koliopoulos G, Martin-Hirsch P, Arbyn M, Prendiville W, Paraskevaidis E. Obstetric outcomes after conservative treatment for intraepithelial or early invasive cervical lesions: systematic review and meta-analysis. Lancet 2006 Feb 11;367(9509):489-98.

12. Sankaranarayanan R, Esmy PO, Rajkumar R, Muwonge R, Swaminathan R, Shanthakumari S, et al. Effect of visual screening on cervical cancer incidence and mortality in Tamil Nadu, India: a cluster-randomised trial. Lancet 2007 Aug 4;370(9585):398-406.

13. Wang JW, Roden RB. Virus-like particles for the prevention of human papillomavirus-associated malignancies. Expert Rev Vaccines 2013 Feb;12(2):129-

41.

14. Chatterjee A. The next generation of HPV vaccines: nonavalent vaccine V503 on the horizon. Expert Rev Vaccines 2014 Nov;13(11):1279-90.

15. Jeronimo J, Bansil P, Lim J, Peck R, Paul P, Amador JJ, et al. A multicountry evaluation of careHPV testing, visual inspection with acetic acid, and papanicolaou testing for the detection of cervical cancer. Int J Gynecol Cancer 2014 Mar;24(3):57685. 
16. Bernard HU. Established and potential strategies against papillomavirus infections. J Antimicrob Chemother 2004 Feb;53(2):137-9.

17. Ramirez-Fort MK, Au SC, Javed SA, Loo DS. Management of cutaneous human papillomavirus infection: pharmacotherapies. Curr Probl Dermatol 2014;45:175-85.

18. Tao XH, Guan Y, Shao D, Xue W, Ye FS, Wang M, et al. Efficacy and safety of photodynamic therapy for cervical intraepithelial neoplasia: A systemic review. Photodiagnosis Photodyn Ther 2014 Mar 10;11:(2):104-12.

19. Hillemanns P, Garcia F, Petry KU, Dvorak V, Sadovsky O, Iversen OE, et al. A randomized study of hexaminolevulinate photodynamic therapy in patients with cervical intraepithelial neoplasia 1/2. Am J Obstet Gynecol 2015 Apr;212(4):465 e17.

20. Clamp PJ, Saunders MW. Systematic review of intralesional cidofovir dosing regimens in the treatment of recurrent respiratory papillomatosis. Int J Pediatr Otorhinolaryngol 2013 Mar;77(3):323-8.

21. Snoeck R, Noel JC, Muller C, De Clercq E, Bossens M. Cidofovir, a new approach for the treatment of cervix intraepithelial neoplasia grade III (CIN III). J Med Virol 2000 Feb;60(2):205-9.

22. Van Pachterbeke C, Bucella D, Rozenberg S, Manigart Y, Gilles C, Larsimont D, et al. Topical treatment of CIN 2+ by cidofovir: results of a phase II, double-blind, prospective, placebo-controlled study. Gynecol Oncol 2009 Oct;115(1):69-74.

23. McElhiney LFPR. Topical Cidofovir for Treatment of Resistant Viral Infections. Int J Pharm Compd 2006 Sept-Oct;10(5):324-8.

24. Soma MA, Albert DM. Cidofovir: to use or not to use? Current opinion in otolaryngology \& head and neck surgery 2008 Feb;16(1):86-90.

25. Slade HB, Owens ML, Tomai MA, Miller RL. Imiquimod 5\% cream (Aldara). Expert Opin Investig Drugs 1998 Mar;7(3):437-49.

26. Grillo-Ardila CF, Angel-Muller E, Salazar-Diaz LC, Gaitan HG, Ruiz-Parra AI, Lethaby A. Imiquimod for anogenital warts in non-immunocompromised adults. Cochrane Database Syst Rev 2014;11:CD010389.

27. Lin CT, Qiu JT, Wang CJ, Chang SD, Tang YH, Wu PJ, et al. Topical imiquimod treatment for human papillomavirus infection in patients with and without cervical/vaginal intraepithelial neoplasia. Taiwan J Obstet Gynecol 2012

Dec;51(4):533-8.

28. Chen FP. Efficacy of imiquimod 5\% cream for persistent human papillomavirus in genital intraepithelial neoplasm. Taiwan J Obstet Gynecol 2013 Dec;52(4):475-8.

29. Pachman DR, Barton DL, Clayton AC, McGovern RM, Jefferies JA, Novotny PJ, et al. Randomized clinical trial of imiquimod: an adjunct to treating cervical dysplasia. Am J Obstet Gynecol 2012 Jan;206(1):42 e1-7.

30. Tristram A, Hurt CN, Madden T, Powell N, Man S, Hibbitts S, et al. Activity, safety, and feasibility of cidofovir and imiquimod for treatment of vulval intraepithelial neoplasia (RT(3)VIN): a multicentre, open-label, randomised, phase 2 trial. Lancet Oncol 2014 Nov;15(12):1361-8.

31. Rahangdale L, Lippmann QK, Garcia K, Budwit D, Smith JS, van Le L. Topical 5-fluorouracil for treatment of cervical intraepithelial neoplasia 2: a randomized controlled trial. Am J Obstet Gynecol 2013 Dec 31;210(4):314. 32. Gamelin E, Boisdron-Celle M, Guerin-Meyer V, Delva R, Lortholary A, Genevieve F, et al. Correlation between uracil and dihydrouracil plasma ratio, fluorouracil (5-FU) pharmacokinetic parameters, and tolerance in patients with
Formatted: French (France)

Formatted: English (United Kingdom)

Formatted: English (United Kingdom) 
advanced colorectal cancer: A potential interest for predicting 5-FU toxicity and determining optimal 5-FU dosage. J Clin Oncol 1999 Apr;17(4):1105.

33. Chakalova G, Ganchev G. Local administration of interferon-alpha in cases of cervical intraepithelial neoplasia associated with human papillomavirus infection. J BUON 2004 Oct-Dec;9(4):399-402.

34. King M, Kumar P, Michel D, Batta R, Foldvari M. In vivo sustained dermal delivery and pharmacokinetics of interferon alpha in biphasic vesicles after topical application. Eur J Pharm Biopharm 2013 Aug;84(3):532-9.

35. Rosales R, Rosales C. Immune therapy for human papillomaviruses-related cancers. World J Clin Oncol 2014 Dec 10;5(5):1002-19.

36. Corona Gutierrez CM, Tinoco A, Navarro T, Contreras ML, Cortes RR, Calzado $\mathrm{P}$, et al. Therapeutic vaccination with MVA E2 can eliminate precancerous lesions (CIN 1, CIN 2, and CIN 3) associated with infection by oncogenic human papillomavirus. Hum Gene Ther 2004 May;15(5):421-31.

37. Rosales R, Lopez-Contreras M, Rosales C, Magallanes-Molina JR, GonzalezVergara R, Arroyo-Cazarez JM, et al. Regression of human papillomavirus intraepithelial lesions is induced by MVA E2 therapeutic vaccine. Hum Gene Ther 2014 Dec;25(12):1035-49.

38. Verheust C, Goossens M, Pauwels K, Breyer D. Biosafety aspects of modified vaccinia virus Ankara (MVA)-based vectors used for gene therapy or vaccination. Vaccine 2012 Mar 30;30(16):2623-32.

39. Bagarazzi ML, Yan J, Morrow MP, Shen X, Parker RL, Lee JC, et al. Immunotherapy against HPV16/18 generates potent TH1 and cytotoxic cellular immune responses. Sci Transl Med 2012 Oct 10;4(155):155ra38.

40. Kumar S, Jena L, Sahoo M, Kakde M, Daf S, Varma AK. In Silico Docking to Explicate Interface between Plant-Originated Inhibitors and E6 Oncogenic Protein of Highly Threatening Human Papillomavirus 18. Genomics Inform 2015 Jun;13(2):607.

41. Palasap A, Limpaiboon T, Boonsiri P, Thapphasaraphong S, Daduang S, Suwannalert P, et al. Cytotoxic effects of Phytophenolics from Caesalpinia mimosoides Lamk on cervical carcinoma cell lines through an apoptotic pathway. Asian Pac J Cancer Prev 2014;15(1):449-54.

42. Mondal A, Chatterji U. Artemisinin Represses Telomerase Subunits and Induces Apoptosis in HPV-39 Infected Human Cervical Cancer Cells. J Cell Biochem 2015 Sep;116(9):1968-81.

43. Goodrich SK, Schlegel CR, Wang G, Belinson JL. Use of artemisinin and its derivatives to treat HPV-infected/transformed cells and cervical cancer: a review. Future Oncol 2014 Mar;10(4):647-54.

44. Jansen FH, Adoubi I, J CK, T DEC, Jansen N, Tschulakow A, et al. First study of oral Artenimol-R in advanced cervical cancer: clinical benefit, tolerability and tumor markers. Anticancer Res 2011 Dec;31(12):4417-22.

45. Munagala R, Kausar H, Munjal C, Gupta RC. Withaferin A induces p53dependent apoptosis by repression of HPV oncogenes and upregulation of tumor suppressor proteins in human cervical cancer cells. Carcinogenesis 2011

Nov;32(11):1697-705.

46. Garcia-Zepeda SP, Garcia-Villa E, Diaz-Chavez J, Hernandez-Pando R, Gariglio P. Resveratrol induces cell death in cervical cancer cells through apoptosis and autophagy. Eur J Cancer Prev 2013 Nov;22(6):577-84.

47. Garcia FA, Cornelison T, Nuno T, Greenspan DL, Byron JW, Hsu CH, et al. Results of a phase II randomized, double-blind, placebo-controlled trial of

Formatted: Spanish (Spain)

Formatted: English (United Kingdom) 
Polyphenon E in women with persistent high-risk HPV infection and low-grade cervical intraepithelial neoplasia. Gynecol Oncol 2014 Feb;132(2):377-82.

48. Yim EK, Lee MJ, Lee KH, Um SJ, Park JS. Antiproliferative and antiviral mechanisms of ursolic acid and dexamethasone in cervical carcinoma cell lines. Int J Gynecol Cancer 2006 Nov-Dec;16(6):2023-31.

49. Saha SK, Khuda-Bukhsh AR. Berberine alters epigenetic modifications, disrupts microtubule network, and modulates HPV-18 E6-E7 oncoproteins by targeting p53 in cervical cancer cell HeLa: a mechanistic study including molecular docking. Eur J Pharmacol 2014 Dec 5;744:132-46.

50. Lee HG, Yu KA, Oh WK, Baeg TW, Oh HC, Ahn JS, et al. Inhibitory effect of jaceosidin isolated from Artemisiaargyi on the function of E6 and E7 oncoproteins of HPV 16. J Ethnopharmacol 2005 Apr 26;98(3):339-43.

51. Basu P, Dutta S, Begum R, Mittal S, Dutta PD, Bharti AC, et al. Clearance of cervical human papillomavirus infection by topical application of curcumin and curcumin containing polyherbal cream: a phase II randomized controlled study. Asian Pac J Cancer Prev 2013;14(10):5753-9.

52. Bell MC, Crowley-Nowick P, Bradlow HL, Sepkovic DW, SchmidtGrimminger D, Howell P, et al. Placebo-controlled trial of indole-3-carbinol in the treatment of CIN. Gynecol Oncol 2000 Aug;78(2):123-9.

53. Potempa M, Lee SK, Wolfenden R, Swanstrom R. The triple threat of HIV-1 protease inhibitors. Curr Top Microbiol Immunol 2015;389:203-41.

54. Piccinini M, Rinaudo MT, Chiapello N, Ricotti E, Baldovino S, Mostert M, et al. The human 26S proteasome is a target of antiretroviral agents. Aids $2002 \mathrm{Mar}$ 29;16(5):693-700.

55. Piccinini M, Mostert M, Rinaudo MT. Proteasomes as drug targets. Curr Drug Targets 2003 Nov;4(8):657-71.

56. Piccinini M, Rinaudo MT, Anselmino A, Buccinna B, Ramondetti C, Dematteis A, et al. The HIV protease inhibitors nelfinavir and saquinavir, but not a variety of HIV reverse transcriptase inhibitors, adversely affect human proteasome function. Antivir Ther 2005;10(2):215-23.

57. Banks L, Pim D, Thomas M. Viruses and the 26S proteasome: hacking into destruction. Trends Biochem Sci 2003 Aug;28(8):452-9.

58. Hampson L, Kitchener HC, Hampson IN. Specific HIV protease inhibitors inhibit the ability of HPV16 E6 to degrade p53 and selectively kill E6-dependent cervical carcinoma cells in vitro. Antivir Ther 2006;11(6):813-25.

59. Kwara A, Delong A, Rezk N, Hogan J, Burtwell H, Chapman S, et al. Antiretroviral drug concentrations and HIV RNA in the genital tract of HIV-infected women receiving long-term highly active antiretroviral therapy. Clin Infect Dis 2008 Mar 1;46(5):719-25.

60. Lahiri CD, Dugan KB, Xie X, Reimers L, Burk RD, Anastos K, et al. Oral Lopinavir Use and Human Papillomavirus Infection in HIV-positive Women. J Acquir Immune Defic Syndr 2015 Jul 11.

61. Batman G, Oliver AW, Zehbe I, Richard C, Hampson L, Hampson IN. Lopinavir up-regulates expression of the antiviral protein ribonuclease $\mathrm{L}$ in human papillomavirus-positive cervical carcinoma cells. Antivir Ther 2011;16(4):515-25. 62. Bernstein WB, Dennis PA. Repositioning HIV protease inhibitors as cancer therapeutics. Curr Opin HIV AIDS 2008 Nov;3(6):666-75.

63. Chow WA, Jiang C, Guan M. Anti-HIV drugs for cancer therapeutics: back to the future? Lancet Oncol 2009 Jan;10(1):61-71. 
64. Batman G, Hampson L, Hampson IN. Lessons from repurposing HIV drugs: a prospective novel strategy for drug design. Future Virology 2011

2014/04/13;6(9):1021-3.

65. Bruning A, Gingelmaier A, Friese K, Mylonas I. New prospects for nelfinavir in non-HIV-related diseases. Curr Mol Pharmacol 2010 Jun;3(2):91-7.

66. Hampson L, Oliver AW, Hampson IN. Using HIV drugs to target human papilloma virus. Expert Rev Anti Infect Ther 2014 Sep;12(9):1021-3.

67. Shchukina VN, Loginova S, Borisevich SV, Bondarev VP. [Experience with empirical treatment of severe acute respiratory syndrome due to coronavirus, genotype IV]. Antibiot Khimioter 2011;56(7-8):42-6.

68. de Wilde AH, Jochmans D, Posthuma CC, Zevenhoven-Dobbe JC, van Nieuwkoop S, Bestebroer TM, et al. Screening of an FDA-approved compound library identifies four small-molecule inhibitors of Middle East respiratory syndrome coronavirus replication in cell culture. Antimicrob Agents Chemother 2014 Aug;58(8):4875-84.

69. Chan JF, Lau SK, To KK, Cheng VC, Woo PC, Yuen KY. Middle East respiratory syndrome coronavirus: another zoonotic betacoronavirus causing SARSlike disease. Clin Microbiol Rev 2015 Apr;28(2):465-522.

70. Barillari G, Iovane A, Bacigalupo I, Palladino C, Bellino S, Leone P, et al. Ritonavir or saquinavir impairs the invasion of cervical intraepithelial neoplasia cells via a reduction of MMP expression and activity. AIDS 2012 May 15;26(8):909-19.

71. Lucci. A Phase II Single-arm Intervention Trial of Nelfinavir in Patients With Grade 2/3 or 3 Cervical Intraepithelial Neoplasia. 2013 [cited; Available from: https://clinicaltrials.gov/ct2/show/NCT01925378

72. Hampson I. Lopinavir as a Topical Treatment (LOTT) trial for HPV-related cervical dysplasia in HIV negative women. 2014 [cited; Available from: http://www.controlled-trials.com/ISRCTN48776874

73. Sargent A, Bailey A, Almonte M, Turner A, Thomson C, Peto J, et al. Prevalence of type-specific HPV infection by age and grade of cervical cytology: data from the ARTISTIC trial. Br J Cancer 2008 May 20;98(10):1704-9.

74. Pasley MV, Martinez M, Hermes A, d'Amico R, Nilius A. Safety and efficacy of lopinavir/ritonavir during pregnancy: a systematic review. AIDS Rev 2013 JanMar;15(1):38-48. 